\title{
Predicting the crack path in a wedge under a concentrated tensile force by means of variational principle
}

\author{
Nataliya S. Popova, Evgeny M. Morozov \\ National Research Nuclear University MEPhi (Moscow Engineering Physics Institute), Russia \\ pakhalina0990@gmail.com, evgeny.morozof@gmail.com
}

Yury G. Matvienko

Mechanical Engineering Research Institute of the Russian Academy of Sciences, Russia ygmatvienko@gmail.com, bttp://orcid.org/0000-0003-2367-0966

ABSTRACT. Variational principle of brittle fracture mechanics is employed to predict the crack path in an infinite wedge under a concentrated tensile force. The weight function in basic equation of variational problem is assumed to be proportional to the maximum strain in the uncracked wedge. Obtained equation for solving the variational problem allowed predicting the crack path in general. The predicted crack path is in agreement with experimental results obtained in the case of the truncated wedge.

KEYwORDS. Crack path; Variational principle; wedge; Concentrated tensile force.

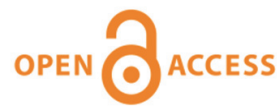

Citation: Popova, N. S., Morozov, E. M. Matvienko, Y, G., Predicting the crack path in a wedge under a concentrated tensile force by means of variational principle, Frattura ed Integrità Strutturale, 49 (2019) 267-271.

Received: 14.05 .2019

Accepted: 25.05.2019

Published: 01.07.2019

Copyright: (C) 2019 This is an open access article under the terms of the CC-BY 4.0, which permits unrestricted use, distribution, and reproduction in any medium, provided the original author and source are credited.

\section{INTRODUCTION}

A search of the crack path is one of important problems in the field of brittle and elastic-plastic fracture mechanics. This problem can be solved by means two basic approaches of fracture mechanics, namely, incremental and integral approaches. First approach is based on incremental methods which are widely spread and associated with local criterion. Local criteria allow estimating a fracture angle between directions of the initial crack propagation and succeeding crack increment. Basically, local criteria for determining the crack path under complex mixed mode loading conditions employ an analysis of energy and stress (strain) fields in the vicinity of the crack tip. Possible local criteria can be based on the maximum tangential stress criterion, the maximum tangential strain criterion, the maximum energy release rate criterion, criterion of the minimum energy consumption for fracture, criterion of the strain energy density, the Jintegral concept and etc. The details of modern criteria for predicting the crack path can be found in Refs. (e.g. [1-6]). Integral approach allows predicting the crack path in general and can be based on a variational principle of fracture mechanics [7-9]. The minimum of the certain functional in this principle is assumed to interpret the crack propagation line as a geodesic line on the surface of solids. It should be noted that the functional contains the weight function depending 
on the stress and strain field of the uncracked solid and search functions. In this case, the crack path on the surface is described by means of search functions.

The present paper deals with a variational principle of fracture mechanics to predict the crack path in a wedge under a concentrated tensile force.

\section{THE VARIATIONAL PRINCIPLE IN A SEARCH OF THE CRACK PATH}

7 he crack tip is assumed to be a material particle which has some effective mass [7]. In this case, the crack propagates due to movement of this effective mass at the crack tip. The above-mentioned assumption leads to the variational problem for predicting crack paths and can be given by the following equation

$$
\delta \mathrm{L}=0 \text {. }
$$

The functional L should be determined to solve the variational problem for predicting the crack path in a solid under considered loading conditions. The functional $\mathrm{L}$ in the case of a flat plate can be written as follows

$$
\mathrm{L}=\int_{\mathrm{A}}^{\mathrm{B}} \Phi(\mathrm{x}, \mathrm{y}) \mathrm{ds}, \quad \mathrm{ds}=\sqrt{1+\mathrm{y}^{\prime 2}} \mathrm{dx} .
$$

The weight function in Eq. (1) is denoted as $\Phi(x, y)$. This function is dependent on stresses (or strains) in the uncracked solid. The crack path on the solid surface can be described by the following equation $r=r(x, y)$, where $r$ is the radius-vector. A point belonging to the crack path has Cartesian coordinates $x$ and $y$.

Equation of the crack path is assumed to be an extremal that should be calculated from basic Eqn. (1). A formulation of the variational problem, taking into account the Euler-Lagrange equation, the minimum of the functional $\mathrm{L}$ and the transversally condition, gives well-defined boundary conditions for ends of the crack path, i.e. the crack path should be perpendicular to the free surface of a solid [9].

According to the variational principle, the crack path is interpreted as a geodesic line which is the shortest possible line between two points $A$ and $B$ on the surface of a solid. In this case, the crack propagation line has to satisfy the following condition $\delta \int_{A}^{B} \mathrm{ds}=0$. The crack increment is also assumed to be deviated from the initial direction of crack growth by the stress state. Therefore, a metric of the generalized geodesic line is also determined by the stress state of the untracked body and can be written by the following expression $\mathrm{ds}^{*}=\Phi \mathrm{d}$, i.e. $\delta \int_{\mathrm{A}}^{\mathrm{B}} \mathrm{ds}^{*}=0[7,8]$. It was shown [7-9] that the function $\Phi$ in brittle fracture mechanics is connected with the maximum principal stress or strain in solids without cracks.

To illustrate predicting the crack path by means of variational principle, an infinite wedge under concentrated tensile force $\mathrm{P}$ is analyzed (Fig. 1). The angle between the wedge axis and the lateral surface is marked as $\alpha$.

In this case, the function $\Phi$ in Eq. (2) is assumed to be proportional to the maximum strain $\varepsilon_{1}$ [9]

$$
\Phi(\mathrm{x}, \mathrm{y})=\varepsilon_{1}=v \frac{2 \mathrm{P}}{\pi \mathrm{E}} \frac{\mathrm{x}}{\mathrm{x}^{2}+\mathrm{y}^{2}}
$$

where $\nu$ is Poisson's ratio and $E$ is Young's modulus.

Taking into account the above-mentioned statement, the minimum of the functional $L$ can be written in the following form

$$
\delta \int_{\mathrm{x}_{1}}^{\mathrm{x}_{2}} \frac{2 \nu \mathrm{P}}{\pi \mathrm{E}} \frac{\mathrm{x}}{\mathrm{x}^{2}+\mathrm{y}^{2}} \sqrt{1+\left(\mathrm{y}^{\prime}\right)^{2}} \mathrm{dx}=0
$$

This relationship leads to equation for solving the variational problem in a search of the crack path 
$\frac{y^{\prime \prime}\left(x^{2}+y^{2}\right) x}{1+\left(y^{\prime}\right)^{2}}+y^{\prime}\left(y^{2}-x^{2}\right)+2 x y=0$

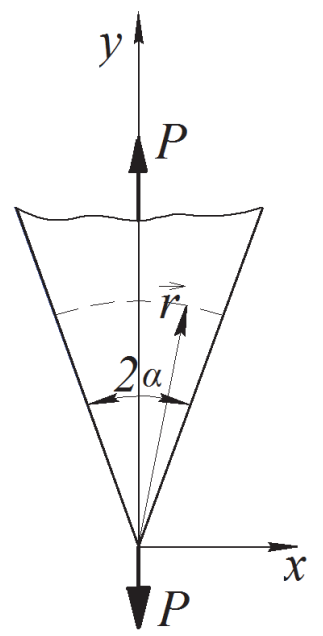

Figure 1: The scheme of an infinite wedge under concentrated tensile force P.

Eqn. (5) can be solved related to $y$ as a function of $x$ to predict the crack path in an infinite wedge under concentrated tensile force $P$. It should be also noted, the crack path is in agreement with the minimum value of the energy lost accompanied by creating a new surface of the crack. In this case, the radius-vector $r$ is constant for the crack path in an infinite wedge under concentrated tensile force $P$ [7]. The results of numerical solution of Eq. (5) are presented in Fig. 2 for two angles $\alpha$ and the radius-vector $\mathrm{r}_{0}$. It can be seen that the crack paths have arc shapes and are perpendicular to the free surface of the truncated wedge as it was expected according the variational principle.

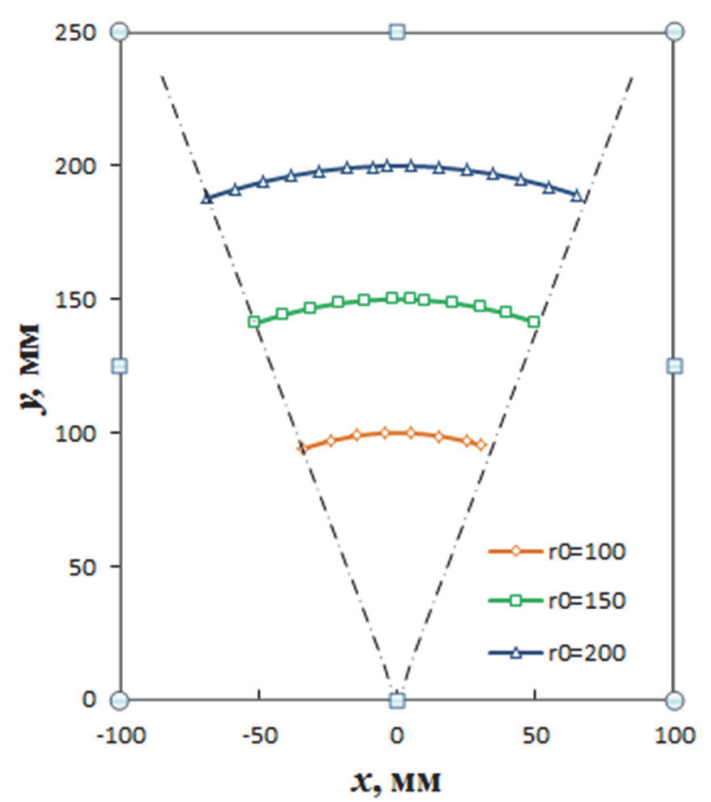

a

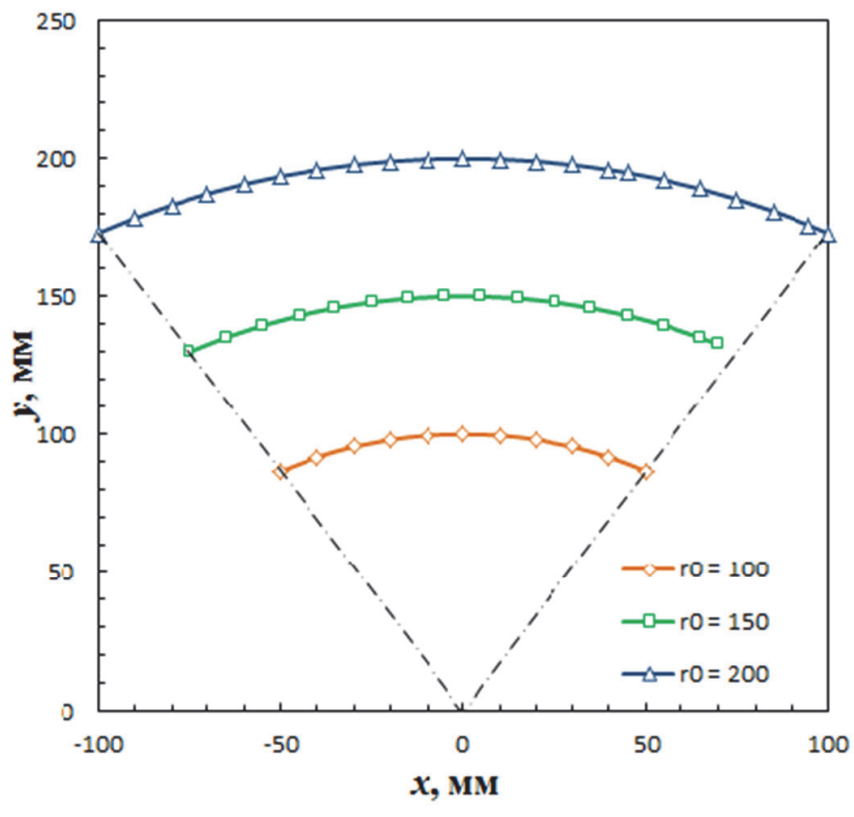

$\mathrm{b}$

Figure 2: Predicted crack paths in an infinite wedge under concentrated tensile force P: (a) $2 \alpha=40^{\circ}$, (b) $2 \alpha=60^{\circ}$. 


\section{VALIDATION OF THE VARIATIONAL PRINCIPLE}

o validate the variational principle for a search of the crack path, the truncated wedge (having $3 \mathrm{~mm}$ thickness) (Fig. 3) is tested under concentrated tensile force $\mathrm{P}$ at room temperature. The angle between the truncated wedge axis and the lateral surface is $20^{\circ}$. The specimen is made from the organic glass. Mechanical properties of the material are the following: Young's modulus $E=3000 \mathrm{MPa}$, ultimate strength $\sigma_{u}=70 \mathrm{MPa}$ and Poisson's ratio $v=0.36$.

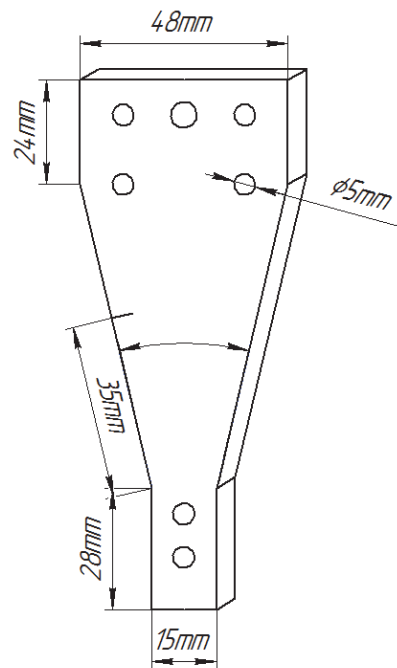

Figure 3: The scheme of the truncated wedge which is tested under concentrated tensile force.

To initiate the crack propagation under concentrated tensile force, the initial notch perpendicular to the lateral surface of the truncated wedge was created. The notch length is $5 \mathrm{~mm}$. The specimen was painted for better visualization of the crack propagation.

It can be seen that the predicted crack path is in agreement with the experimental crack path (Fig. 4). Moreover, the crack propagates perpendicular to free surface of the truncated wedge. This result confirms correctness of the employed model and the variational principle to predict the crack path in the wedge under concentrated tensile load.

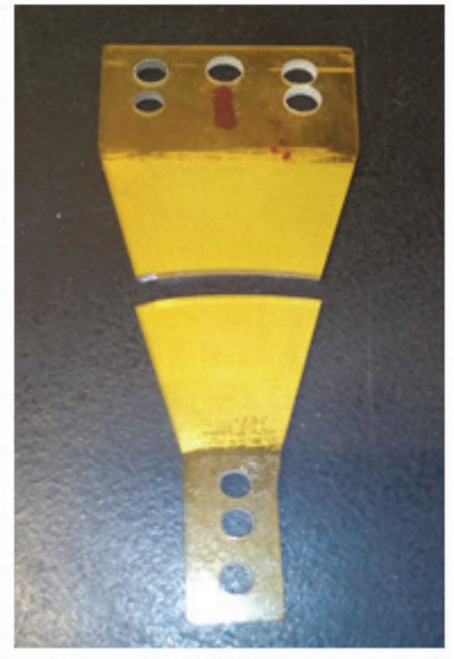

a

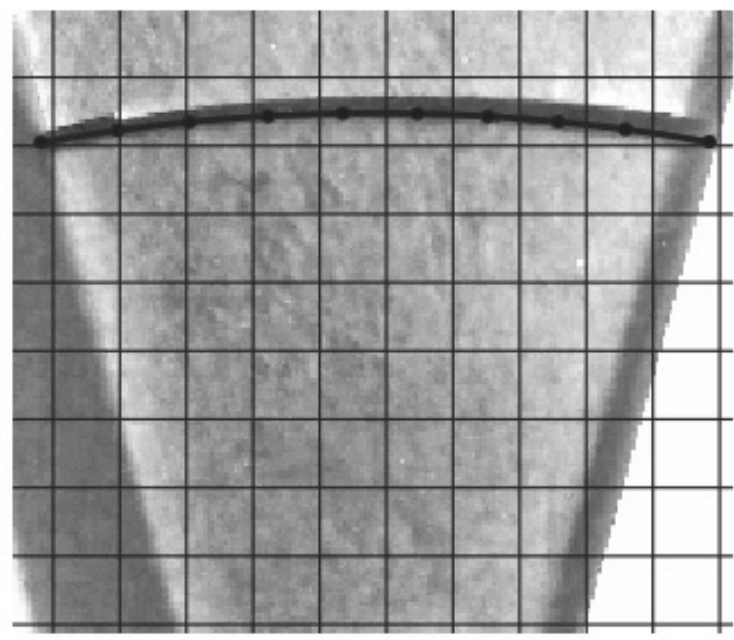

b

Figure 4: Comparison of the experimental crack path (a) with the predicted crack path (b) in the truncated wedge under concentrated tensile load. 


\section{CONCLUSIONS}

$\mathrm{T}$

he paper deals with the variational principle of brittle fracture mechanics which is applied to predict the crack path in the case of the wedge under concentrated tensile load. The basic equations of the variational principle are presented. The following conclusions can be made.

The weight function in basic equations, which is assumed to be proportional to the maximum strain in an infinite wedge under concentrated tensile load, allows predicting crack path in general. To validate the variational principle for a search of the crack path in the case of a wedge under concentrated tensile force $\mathrm{P}$, the truncated wedge is tested at room temperature. The crack paths have arc shapes and are perpendicular to the lateral surface of the truncated wedge as it was expected according the variational principle. The predicted crack path is in agreement with experimental results.

\section{ACKNOWLEDGEMENTS}

$\mathrm{P}$

rofessor Matvienko acknowledges the support of the Russian Science Foundation (project N 18-19-00351).

\section{REFERENCES}

[1] Aliha, M.R.M., Ayatollahi, M.R., Smith, D.J. and Pavier, M.J. (2010). Geometry and size effects on fracture trajectory in a limestone rock under mixed mode loading, Engng. Fract. Mech., 77, pp. 2200-2212.

[2] Sajjadi, S. H., Ostad Ahmad Ghorabi, M. J. and Salimi-Majd, D. (2015). A novel mixed-mode brittle fracture criterion for crack growth path prediction under static and fatigue loading, Fatigue Fract. Eng. Mater. Struct., 38, pp. 13721382.

[3] Mirsayar, M.M., Berto, F., Aliha, M.R.M. and Park, P. (2016). Strain-based criteria for mixed-mode fracture of polycrystalline graphite, Engng. Fract. Mech., 156, pp. 114-123.

[4] Pook, L.P. (2016). The linear elastic analysis of cracked bodies, crack paths and some practical crack path examples, Eng. Fract. Mech., 167, pp. 2-19.

[5] Berto, F. and Gomez, J. (2017). Notched plates in mixed mode loading (I+ II): a review based on the local strain energy density and the cohesive zone mode, Engineering Solid Mechanics, 5, pp. 1-8.

[6] Matvienko, Yu.G. (2012). Maximum Average Tangential Stress Criterion for Prediction of the Crack Path, Int. J. Fract., 176, pp. 113-118.

[7] Parton, V.Z. and Morozov, E.M. (1989). Mechanics of Elastic-Plastic Fracture, Hemisphere publ.: N.Y.

[8] Morozov, E.M. (1998) Some Heuristic Models of Propageting Cracks. In FRACTURE: A Topical Encyclopedia of Current Knowledge (Cherepanov, G.P., Ed.), Krieger Publ. Comp.: Florida.

[9] Matvienko, Y.G., Morozov, E.M. (2017). Two basic approaches in a search of the crack propagation angle, Fatigue Fract. Eng. Mater. Struct., 40, pp. 1191-1200. 